This is the accepted manuscript of an article published by Taylor \& Francis in Aging and Mental Health on November 15, 2019, available online: https://doi.org/10.1080/13607863.2019.1691144

\title{
Sources of Well-Being for Older Adults With and Without Dementia in Residential Care: Relations to Presence of Meaning and Life Satisfaction
}

\author{
Laura Dewitte ${ }^{1,2}$ - ORCID: 0000-0002-8383-680, Twitter: @Laura_Dewitte \\ Prof. Dr. Mathieu Vandenbulcke ${ }^{1,3}$ - ORCID: 0000-0001-9765-1499 \\ Tine Schellekens ${ }^{1}$ - ORCID: 0000-0002-9234-7460 \\ Prof. Dr. Jessie Dezutter ${ }^{1}$ - ORCID: 0000-0002-3457-5334 \\ ${ }^{1}$ KU Leuven, Leuven, Belgium \\ ${ }^{2}$ Research Foundation Flanders, Brussels, Belgium \\ ${ }^{3}$ University Psychiatric Centre KU Leuven, Leuven, Belgium
}

Correspondence concerning this article should be addressed to:

Laura Dewitte, Faculty of Psychology and Educational Sciences, KU Leuven, Tiensestraat 102 - box 3717, Belgium. +32 16/37.42.54, laura.dewitte@kuleuven.be

\section{Funding}

This work was supported by the Research Foundation Flanders under Grant number $1109417 \mathrm{~N}$ (to LD).

\section{Acknowledgements}

We wish to thank the participating residential care settings and residents. We thank our master thesis students for their help in collecting the data.

\section{Disclosure of Interest}

The authors report no conflict of interest. 


\section{Abstract}

Objectives: To explore what sources of well-being are rated meaningful by older adults in residential care and how they are related to two important well-being outcomes.

Method: Two cross-sectional questionnaire studies were conducted in a sample of care residents without cognitive disability $(n=329)$ and with Alzheimer's disease $(n=104)$. Structural equation modelling was used to test a hypothesized and exploratory model of different sources as predictors of presence of meaning in life (POM) and satisfaction with life (SWL).

Results: Family and Health were rated most meaningful by residents with and without dementia. In both studies, the hypothesized model showed adequate fit with the data. For cognitively intact residents, Personal Growth, Spirituality/Religion, and Interpersonal Relationships predicted POM, while Family and Leisure predicted SWL. Exploratory testing identified Leisure as a possible additional predictor of POM. For residents with Alzheimer's disease, Personal Growth and Society/Community predicted POM, while Family predicted SWL.

Conclusion: For older adults in residential care, many sources of well-being remain highly meaningful and some are directly related to the experience of meaning and life satisfaction. Both for residents with and without dementia, continued or increased investment in moments that foster personal growth and family relationships might be especially valuable.

Key words:

Meaning in life, eudaimonic well-being, hedonic well-being, nursing home, Alzheimer's disease 


\section{Introduction}

Old age inevitably comes with challenges and losses that require adaptation. Older adults living in long-term residential care face particular challenges compared to their counterparts living in the community. They are more likely to experience depressive symptoms or depression, show suicidal ideation and behavior, and report lower psychological well-being and personal meaning (Anstey, von Sanden, Sargent-Cox, \& Luszcz, 2007; Fry, 2000; Gleeson, Hafford-Letchfield, Quaife, Collins, \& Flynn, 2018).

How best to support older adults in residential settings to maintain or enhance their well-being remains a prominent question for old age researchers, policy makers, and care workers. A necessary foundation when developing clear guidelines for practice is an understanding of what well-being implies for older adults in residential care and what sources support it. In this contribution, we briefly discuss the current state in psychological well-being research and its relevance for old age care and we report on to two empirical studies focusing on sources of well-being in residential care.

\section{Hedonic and Eudaimonic Well-Being}

Tracing back to ancient Greek philosophical traditions of hedonia and eudaimonia, contemporary psychology distinguishes between two approaches to well-being (Henderson \& Knight, 2012; Huta, 2016). Psychological research into hedonic or subjective well-being focuses on affective and cognitive evaluations of life quality (e.g., positive emotions, happiness, life satisfaction) (Keyes, Shmotkin, \& Ryff, 2002), whereas research into eudaimonic or psychological well-being focuses on human potential and thriving (e.g., meaning, personal growth, authenticity) (Huta, 2018; Ryff, 2013). Hedonic well-being has been argued to be rooted more in nature and therefore to be more related to the maximalization of pleasure, the avoidance of pain, and negative emotions. The focus is thus more on satisfaction of basic needs and desires in the present (Baumeister, Vohs, Aaker, \& 
Garbinsky, 2013). In line, hedonic well-being has been linked to concepts such as materialistic consumption and leisure activities (Baumeister et al., 2013; Kuykendall, Tay, \& $\mathrm{Ng}, 2015$ ). Eudaimonic well-being, on the other hand, has been argued to be rooted more in culture and to be about linking past, present, and future (Baumeister et al., 2013). It refers to a broader idea of well-being, including aspects beyond the self, such as investing in qualitative relationships and engaging in meaningful behavior.

Two principal concepts within each tradition are life satisfaction (hedonic) and meaning in life (eudaimonic) . Life satisfaction can be understood as a long-term, cognitive evaluation of one's life in light of one's beliefs and expectations (Keyes et al., 2002). Meaning in life is currently understood as the experience of knowing who you are, what the world is like, and how you fit in it; of having goals and direction in life; and of feeling that life matters (Martela \& Steger, 2016; Reker \& Wong, 1988).

Hedonic and eudaimonic well-being can be drawn from different sources. These sources are personally relevant life domains, contexts, or internal states that make life enjoyable and/or meaningful, such as family, work, personal growth, creativity, religion, etc. (Bar-Tur, Savaya, \& Prager, 2001; Delle Fave, Brdar, Wissing, \& Vella-Brodrick, 2013). While people differ in the sources they find important, some sources, such as family and interpersonal relationships, are consistently identified as significant by the majority of people (Glaw, Kable, Hazelton, \& Inder, 2017; Lambert et al., 2010).

Sources have been mostly approached from the view-point of eudaimonic well-being and therefore called sources of meaning. However, some sources might be more important for eudaimonic well-being, while others might contribute more to hedonic well-being. In one of the only empirical tests of this distinction in a large international sample, Delle Fave et al. (2013) found that Family, Interpersonal Relationships, Personal Growth, and Community \& Society contributed most to the prediction of general meaning, while Family, Work, and 
Interpersonal Relationships contributed to life satisfaction. However, as noted by the authors, an important restriction of the study was the limited age range (30-51).

Other authors have also found that meaning in life scores are most strongly explained by the sources family and relationships (Grouden \& Jose, 2015; Lambert et al., 2010; Lambert et al., 2013), while happiness has also been associated with more satisfying interpersonal relationships with family and friends (Diener \& Seligman, 2002).

\section{Well-Being in Old Age Residential Care}

The studies described above have focused primarily on young and middle adulthood. However, as people grow older, they might show shifts in the key sources that contribute to their well-being, in response to changing abilities and circumstances inherent to old age. For example, in line with Tornstam's gerotranscendence theory-which proposes that old age is accompanied by 'a shift in meta-perspective from a materialistic and rational view to a more cosmic and transcendent one' (Tornstam, 1989, p. 55)—more individualistic sources such as personal growth and materialistic concerns tend to become less important, while more communal and transcendental sources such as social commitment, spirituality and religiosity tend to become of greater relevance (Bar-Tur et al., 2001; Schnell, 2009). However, for older adults living in the community, sources have been shown to be relatively stable (Bar-Tur et al., 2001; Koenig, King, \& Carson, 2012; Penick \& Fallshore, 2005). For older adults in residential care, in contrast, many important sources are no longer easily accessible. Relocation to residential care can involve the disruption of personal involvements in the community, and for some adults, the stress associated with the relocation may cause them to take less initiative and behave more disengaged (Bar-Tur \& Prager, 1996). This might be why older adults in residential care in one study scored lower on meaningfulness for almost half of the sources investigated, compared to community-residing older adults (Bar-Tur \& Prager, 1996). 
Care settings have the task of supporting opportunities for meaningful social engagement and activity, in line with the values and important life areas of each resident. However, settings often struggle to balance physical care needs and psychosocial needs, and constraints in time and resources often compete with the provision of person-centered care (Smith, Towers, Palmer, Beecham, \& Welch, 2017). In residential care, the personal challenges of ageing are thus accompanied by organizational challenges, making the question of meaningful sources of well-being more pressing.

An important subgroup of older residents face an extra challenge: dementia. Living in residential care with dementia can be accompanied by feelings of loss, isolation, worthlessness, confinement, and boredom (Clare, Rowlands, Bruce, Surr, \& Downs, 2008). Many social roles, activities, or environments that used to contribute to well-being can become even more out of reach. For example, living in a closed ward can restrict freedom of movement, and physical and cognitive challenges can complicate communication and activities such as reading and walking.

Hampered access to or less involvement in longstanding sources of well-being may be one reason for the observation that both eudaimonic and hedonic well-being (personal meaning, mood, depressive symptoms) may be lower for older adults in residential care than in the community (Fry, 2000). Identifying and strengthening those sources that are evaluated as important by the older adults themselves as well as linked to well-being outcomes is therefore a promising avenue for improving the lives of older adults in residential care.

\section{Present study}

The aim of the present paper is twofold. First, we explore what sources are considered most meaningful by older adults in residential care, with and without dementia. Second, we test whether sources are differentially related to two main outcomes, each central to one of the well-being traditions: the experience of life satisfaction (hedonic) and meaning in life 
(eudaimonic). Prior to data-analysis and (part of the) data-collection, the study was registered on the Open Science Framework (osf.io/q86jm/, known deviations from registration: osf.io/8whuy).Few studies have made the distinction between sources of hedonic versus eudaimonic well-being, and most focus on an investigation of the meaningfulness or importance of the sources themselves (cf. our first aim). However, sources might be very salient and therefore rated high on meaningfulness, but they may not contribute to the overall experience of meaning or other aspects of well-being (Grouden \& Jose, 2015).

Based on the existing theoretical and empirical work on sources of hedonic and eudaimonic well-being discussed in this introduction, we expected some sources to be related to both outcomes, and others only to either life satisfaction or meaning in life. An overview of the hypotheses with references are listed in the registration document (osf.io/q86jm/). Figure 1 shows the hypothesized model. Previous work has provided indirect indications for our hypotheses but the study is no exact replication of previous findings, especially given the different population. Therefore, we also explored different potential paths using full exploratory models, and we did not correct for multiple testing, emphasizing the exploratory over the confirmatory nature of the research. Study 1 focuses on nursing home residents without cognitive disorder, Study 2 on residents with a diagnosis of Alzheimer's disease. Data of the samples were collected in different projects at different times, therefore they are handled separately.

In line with existing literature, we expected Family, Interpersonal Relationships, and Spirituality/Religion to predict both presence of meaning in life and life satisfaction for older adults in residential care (with and without dementia) (Delle Fave et al., 2013; Diener \& Seligman, 2002; Grouden \& Jose, 2015; Koenig et al., 2012; Lambert et al., 2013). Furthermore, in line with the hedonic tradition, we expected Standard of Living to predict life satisfaction but not meaning (Baumeister et al., 2013). We also added some tentative paths to 
our model. We expected that Society \& Community and Personal Growth might predict meaning in life (Baumeister et al., 2013; Delle Fave et al., 2013), while Leisure might predict life satisfaction (Kuykendall et al., 2015). Health, finally, might also predict life satisfaction (Baumeister et al., 2013), although in an older population, physical health may not be straightforwardly related to life satisfaction (Puvill, Lindenberg, de Craen, Slaets, \& Westendorp, 2016).

\section{Methods}

\section{General method}

\section{Measures}

For all three measures, a Dutch translation was used and the original 7-point scales were restricted to a 4-point scale to lessen the cognitive burden on participants.

Life satisfaction. The 5-item Satisfaction with Life Scale (SWLS; Diener, Emmons, Larsen, \& Griffin, 1985) was used to measure life satisfaction. ${ }^{1}$ The items (e.g., 'So far I have gotten the important things I want in life.') were rated on a scale from 1 (not at all agree) to 4 (totally agree) and a mean score was calculated. Cronbach's alpha in was .765 in Study 1 and .834 in Study 2.

Presence of meaning in life. The 3-item short form of the Meaning in Life Questionnaire, Presence of Meaning Subscale (POM; Steger \& Samman, 2012) was used to measure presence of meaning in life. The items (e.g. 'I have a clear sense of what makes my life meaningful.') were rated on a scale from 1 (never) to 4 (always) and a mean score was calculated. Cronbach's alpha was .753 in Study 1 and .787 in Study 2.

Sources of meaning. Sources of meaning were derived from the Eudaimonic and Hedonic Happiness Investigation (EHHI; Delle Fave, Brdar, Freire, Vella-Brodrick, \&

\footnotetext{
${ }^{1}$ The data from this scale in Study 1 was also used in a previous published paper focusing on the role of forgiveness and ego-integrity in late life functioning (Derdaele, Toussaint, Thauvoye, \& Dezutter, 2017).
} 
Wissing, 2011; Delle Fave et al., 2013). The degree of meaningfulness of nine life domains (Family, Standard of Living, Interpersonal Relationships, Health, Personal Growth, Spirituality/Religion, Society \& Community, Leisure, and Work) were rated on a scale from 1 (not at all meaningful) to 4 (very meaningful).

\section{Statistical Analyses}

Descriptive and preliminary analyses were performed in SPSS 24/25. The hypothesized path model (Figure 1) was tested in R using the lavaan package for structural equation modelling (SEM) (Rosseel, 2012). Structural equation modeling is a flexible extension of the general linear model; path analysis is one of the most straightforward forms of SEM, which only includes observed variables (as opposed to latent variables). A path analysis allows to test simultaneously the presumed causal relationships between variables expressed in a structural model (Kline, 2005). Full information likelihood estimation (FIML) was used to handle missing data, with missing data assumed to be missing at random. With FIML, all available data per case (complete and non-complete) are used in the estimation process, which produces better (less biased) parameter estimates than a complete case analysis. To minimize bias in the results because of non-normality in the data, the MLR estimator robust to non-normality was used (Rosseel, 2012). Standard fit indices were used to assess model fit: the $\chi^{2}$ Index should be as small as possible, the Comparative Fit Index (CFI) larger than .90, and the Root Mean Square Error of Approximation (RMSEA) and Standardized Root Mean Square Residual (SRMR) smaller than 0.08 (Kline, 2005). Age was included as control variable because of the wide age-range and evidence for a possible link between age and our outcome measures (e.g., Enkvist, Ekström, \& Elmståhl, 2012; Steger, Oishi, \& Kashdan, 2009). 


\section{Procedure Study 1}

The study was part of a larger research project on well-being and meaning in life in residential care. Psychology master and PhD students contacted residential settings asking for collaboration. The settings that agreed provided a list with potential participants based on the exclusion criteria. Between February 2016 and April 2016, these residents were visited in their private rooms and received comprehensive information on the study, after which written informed consent was asked. If participants provided consent, a structured, standardized interview was conducted by means of a questionnaire. The students received training to ensure they approached the residents appropriately and administered the interviews in a standardized way. The study was approved by the ethics committee of KU Leuven (SMEC ID G-201507285). We included as many participants as possible within the provided time frame of data collection. Exclusion criteria were age younger than 65, non-Dutch speaking, temporary stay in the setting, severe hearing or speech impairment, or (suspected) cognitive impairment/disorder.

\section{Procedure Study 2}

The study was part of a larger research project on well-being and meaning in life for older adults with Alzheimer's disease (osf.io/549je). In a first phase, we contacted different residential settings with information on the study and asked for their collaboration. The settings that agreed provided a list with potential participants based on the exclusion criteria. Between November 2017 and February 2018, residents who had provided written consent and had participated in an earlier wave of the study were visited in their private rooms a second time. Comprehensive information on the study was repeated, if necessary adapted to the cognitive abilities of the specific resident, and continued consent was verbally verified. A structured, standardized interview was conducted by means of a questionnaire. Interviewers were the first and third author, who both had earlier clinical experience. Throughout the 
interview, they remained sensitive to any signs of distress or refusal. The study was approved by the ethics committee of KU Leuven (SMEC ID G-201608612). We included as many participants as possible within the provided time frame of data collection. Exclusion criteria were age younger than 65 , non-Dutch speaking, temporary stay in the residential setting, or having a severe hearing or speech impairment.

\section{Results}

\section{Study 1}

\section{Sample}

Participants were a convenience sample of 329 residential care residents ( 233 female, 96 male) without cognitive impairment/disorder, from 27 nursing homes in Flanders. Mean age was $87(S D=6.04$, range $=65-99)$. Seventeen residents were single $(5 \%), 36$ married (11\%), 261 widowed (79\%), 13 divorced (4\%) and for $2(1 \%)$ civil state was missing.

\section{Preliminary Analyses}

Descriptives are presented in Table 1. Family and Health were rated as most meaningful by most of the participants, followed by Interpersonal Relationships and Leisure. Society \& Community, Spirituality/Religion, and Personal Growth received the lowest scores, but were still rated as (very or a little) meaningful by more than half of the participants.

Correlations are displayed in Table 2 . Age is correlated significantly with only one variable: Spirituality/Religion. For the sources, the most notable correlations (at least moderate effect size according to Cohen's classification), are between Interpersonal Relationships and Society \& Community, between Personal Growth and Society \& Community, and between Personal Growth and Leisure.

Six sources were significantly and positively correlated with POM: Family, Interpersonal Relationships, Leisure, Work, Spirituality/Religion, and Personal Growth. Four 
sources were significantly and positively correlated with SWLS: Family, Leisure, Society \& Community, and Spirituality/Religion.

\section{Confirmatory Path Model}

The hypothesized path model showed acceptable fit with the data $\left[\chi^{2}(5)=13.143, p=\right.$ $0.022 ; \mathrm{CFI}=.897 ; \mathrm{RMSEA}=.067 ; \mathrm{SRMR}=.021]$. Six paths of the model were significant: Personal Growth $(\beta=0.242, p<0.001)$, Spirituality/Religion $(\beta=0.151, p=0.005)$, and Interpersonal Relationships $(\beta=0.132, p=0.020)$ were positively related to POM, while age $(\beta=0.139, p=0.022)$, Family $(\beta=0.140, p=0.011)$, and Leisure $(\beta=0.148, p=0.012)$ were positively related to SWLS. A trimmed model in which all sources not predictive in the first model were removed (but age retained as control variable) was tested and showed good fit $\left[\chi^{2}\right.$ $(5)=8.026, p=0.155 ; \mathrm{CFI}=.954 ; \mathrm{RMSEA}=.044 ; \mathrm{SRMR}=.023]$. This parsimonious model is shown in Figure 2.

\section{Exploratory Analyses}

We tested a fully identified model, to investigate whether paths not included in the initial hypothesized model might be of interest to consider in future studies. The model included age as control variable and all eight sources of Figure 1 as predictors of both POM and SWLS. Besides the significant paths identified in the confirmatory analyses, one extra significant path emerged between Leisure and POM $(\beta=0.131, p=0.012)$.

As a second exploration, we tested a model where Work was included as additional possible predictor of the outcomes. We had no specific hypotheses with regard to this source, as we had little information about its relevance for a retired population. The model showed no significant relation between meaningfulness of Work and either of the outcomes. 


\section{Study 2}

Sample

Participants were a convenience sample of 104 residential care residents ( 81 female, 23 male) from nine nursing homes in Flanders with a diagnosis of (probable) Alzheimer's disease. The mean age was $86(S D=5.69$, range $=71-98)$. Nine residents were single $(9 \%)$, 16 married (15\%), 1 cohabiting (1\%), 72 widowed (69\%), 1 divorced (1\%) and for $5(5 \%)$ civil state was missing.

\section{Preliminary analyses}

Descriptives are presented in Table 1. Health, Family, and Society \& Community were rated as most meaningful by most of the participants, followed by Interpersonal Relationships and Spirituality/Religion. Leisure, Personal Growth, and Standard of Living received the lowest scores, but were still rated as (very or a little) meaningful by more than half of the participants.

Correlations are displayed in Table 3. Age was not correlated with any of the variables. Sources were more strongly correlated with each other than in Study 1 . The strongest correlations, of a large size according to Cohen's classification, were between Family and Spirituality/Religion and between Leisure and Standard of Living, followed by moderate correlations between Personal Growth and Standard of Living, between Family and Society \& Community, and between Personal Growth and Leisure.

Eight sources were significantly and positively correlated with POM: only Health was not. Four sources were significantly and positively correlated with SWLS, the same as in Study 1: Family, Society \& Community, Spirituality/Religion, and Leisure.

\section{Confirmatory Path Model}

The hypothesized path model (Figure 1) showed adequate fit with the data $\left[\chi^{2}(5)=\right.$ $5.736, p=0.333 ; \mathrm{CFI}=.985 ; \mathrm{RMSEA}=.040 ; \mathrm{SRMR}=.022]$. Three paths were significant: 
Personal Growth $(\beta=0.320, p=0.004)$ and Society $\&$ Community $(\beta=0.201, p=0.020)$ were positively related to POM, while Family $(\beta=0.412, p=0.001)$ was positively related to SWLS. A trimmed model in which all sources not predictive in the first model were removed (but age retained as control variable) was tested and also showed good fit $\left[\chi^{2}(3)=3.027, p=\right.$ $0.387 ; \mathrm{CFI}=.999 ; \mathrm{RMSEA}=.009 ; \mathrm{SRMR}=.034]$. This parsimonious model is shown in Figure 3.

\section{Exploratory Analyses}

As in the previous study, a fully identified model was tested in order to identify possible additional paths of interest for future confirmatory studies. However, due to the limited sample size, these exploratory analyses should be read with caution. For POM, no additional predictive paths were found, and the paths significant in the confirmatory analyses were non-significant, probably due to lack of sufficient power. For SWLS, no additional sources were predictive in addition to Family. Similar to Study 1, when Work was added as a source in a second exploratory model, Work was not related to either of the outcome measures.

\section{Discussion}

Two cross-sectional studies examined the sources of well-being for older adults in residential care and their relationship to presence of meaning in life and life satisfaction. Study 1 focused on residents without cognitive disorders, Study 2 focused on residents with probable Alzheimer's disease.

Our first research question involved identifying the sources that were rated as most meaningful by the residents. Like in previous research, the examined sources received overall high ratings on meaningfulness (Bar-Tur et al., 2001). For both studies, and in line with previous results in middle adulthood, Family and Health were rated most meaningful on average, with mean scores above 3.5 on a 4-point scale (Delle Fave et al., 2011). Personal 
Growth was rated relatively less meaningful in both studies (below 3), although still rated very or a little meaningful by more than half of the participants in both samples. In study 1 , Standard of Living and Leisure were ranked relatively higher on meaningfulness than in study 2, while in Study 2, Society \& Community and Spirituality/Religion were ranked relatively higher.

The second aim of the studies was to investigate which sources were predictive of 1) presence of meaning in life and 2) life satisfaction, two main indicators of eudaimonic and hedonic well-being, respectively. The hypothesized model showed adequate fit with the data, however, only some sources were predictive of the outcomes. Family—one of the consistently highest rated sources of meaning in this and previous studies — was a predictor of life satisfaction, both for residents with and without dementia. Somewhat surprisingly, while rated highest on meaningfulness, Family was no significant predictor of presence of meaning. Thus as suggested before, the sources rated highest on meaningfulness are not necessarily most predictive of overall meaning in life (Grouden \& Jose, 2015). Health, for example, scored high in both studies but was not significantly predictive of any of the outcomes. Personal Growth received relatively lower ratings in both groups, but turned up as the strongest predictor of presence of meaning, both for residents with and without dementia.

The trimmed parsimonious models (Figure 2 and 3) fit the data well, but it is important to keep in mind that these are data-driven (i.e., based on the significant paths of the hypothesized model) and not simply generalizable to other samples. We could have somewhat more confidence in the predictors returning in both studies, namely Personal Growth as predictor of presence of meaning and Family as predictor of life satisfaction, which were also identified as predictors in middle adulthood in previous research (Delle Fave et al., 2013). The importance of family relationships across the lifespan is therefore once more emphasized. However, while in middle adulthood, Family was predictive of both life satisfaction and meaning, in our 
sample of older adults it only predicted life satisfaction. A possible explanation might be that building and caring for a family is seen as a core life purpose for many throughout middle adulthood. In very old age, this might no longer be an active goal, but a fulfilled purpose that now provides a feeling of fulfillment and contentment. Another factor to consider is the different analytical approach in this study. We used structural equation modelling (as opposed to two separate regression analyses), which takes into account the interdependence between life satisfaction and meaning and allows to test for the unique contribution of the sources to each outcome variable.

Regarding Personal Growth, Delle Fave et al. (2013) compared three different age groups within middle adulthood (30-34, 35-44, and 45-51), and observed a decline with age in the importance of Personal Growth in predicting presence of meaning. Although this might lead to the expectation that Personal Growth becomes increasingly irrelevant when growing into old age, this does not seem to be the case. Therefore, this decline is probably not linear. Although we should be cautious in formulating direct practical consequences from these results, residential care settings would probably do well in actively sustaining family involvement. Moreover, keeping residents invested in their personal development and combatting the idea that this is reserved for the young, might be a promising strategy to support the experience of meaning in life.

Some sources were significant predictors in one study but not the other (e.g., in Study 1, Spirituality/Religion and Interpersonal Relationships predicted presence of meaning while in Study 2, Society \& Community did) and some hypothesized sources were not significant in either of the studies (Standard of Living, Health). Especially for Health, this might be somewhat surprising as health concerns can be expected to become more important with age. This was indeed evident in the comparison of different age groups in middle adulthood by Delle Fave and colleagues (2013). The older adults in our sample also indicated Health as one 
of the most meaningful sources to them. However, the relation between health and well-being is presumably complicated by many moderating and mediating variables (e.g., actual health status, subjective health, depressive symptoms, social support, etc.) (Puvill et al., 2016).

Future studies are needed to see whether these findings replicate. Overall, less sources emerged as predictors of meaning compared to previous research in middle adulthood (Delle Fave et al., 2013), which might indicate a more narrowed focus as a result of more limited time and resources in old age. However, it might also demonstrate the difficulties that older adults in residential care face to retain previous sources of meaning. Of course, it cannot be ruled out that our smaller sample size prevented us from detecting some effects.

In both studies, exploratory models were tested to identify possible non-hypothesized paths that nonetheless could be interesting to consider in future studies. In study 1, Leisure emerged as a potential predictor of presence of meaning. This finding is in line with the idea that leisure is about more than pleasure and enjoyment, but also supports meaning, through the promotion of connectedness, personal identity, autonomy, and empowerment (Iwasaki et al., 2017). Meaningful and active participation in activities in residential care has indeed been identified as an important contributor to meaning and dignity in qualitative accounts of nursing home residents (Slettebø et al., 2017).

\section{Limitations}

Our studies have some limitations, most evidently the cross-sectional design, small sample sizes, and short measures. However, these are difficult to circumvent when doing research in specific and vulnerable populations. Sources were measured with single-items only, asking how meaningful the sources were experienced in life. It might be interesting in future studies to take into account how enjoyable, accessible, and/or fulfilled these sources are experienced, as finding a source meaningful, might not be enough for it to contribute to wellbeing when it is for example not fulfilled in the current context. For example, this might be a 
reason why the hypothesized association between interpersonal relationships and well-being, which was strong in middle adulthood (Delle Fave et al., 2013) and we theoretically expected to be important in old age as well, was not found in our study. The current analysis also only allow us to compare between the residents, not within.

Self-selection on the level of the residential settings as well as the residents is another important concern. Care settings and residents that agree to participate in research on the current topics, are likely already more interested in and open to discuss these issues. Common method bias, finally, is another draw-back in questionnaire studies like these, especially for participants with cognitive challenges who might find it more difficult to make nuanced differentiations and might be more vulnerable to certain response tendencies (Podsakoff, MacKenzie, \& Podsakoff, 2012). We tried to mitigate this as much as possible by closely assisting each resident in filling out the items, but method bias still may be one of the reasons why the correlations between the main variables and the residual covariance between presence of meaning and life satisfaction were markedly higher in Study 2 than in Study 1.

\section{Conclusion}

For older adults in residential care, both with and without dementia, many life domains (sources) are still judged as highly personally meaningful, with Family and Health heading the list. Similar to other populations, however, not all sources are directly related to well-being. Family and Personal Growth might be the strongest predictors of respectively life satisfaction and presence of meaning in life. However, these results need replication in larger and preferably more randomly selected samples. Researchers as well as practitioners in the domain of old age are encouraged to build on the current results, so that we can continue to move forward in understanding the needs of older adults in residential care. 


\section{References}

Anstey, K. J., von Sanden, C., Sargent-Cox, K., \& Luszcz, M. A. (2007). Prevalence and risk factors for depression in a longitudinal, population-based study including individuals in the community and residential care. The American Journal of Geriatric Psychiatry, 15(6), 497-505.

Bar-Tur, L., \& Prager, E. (1996). Sources of personal meaning in a sample of young-old and old-old Israelis. Activities, Adaptation \& Aging, 21(2), 59-75.

doi:10.1300/J016v21n02_04

Bar-Tur, L., Savaya, R., \& Prager, E. (2001). Sources of meaning in life for young and old Israeli Jews and Arabs. Journal of Aging Studies, 15(3), 253-269. doi:10.1016/S08904065(01)00022-6

Baumeister, R. F., Vohs, K. D., Aaker, J. L., \& Garbinsky, E. N. (2013). Some key differences between a happy life and a meaningful life. The Journal of Positive Psychology, 8(6), 505-516. doi:10.1080/17439760.2013.830764

Clare, L., Rowlands, J., Bruce, E., Surr, C., \& Downs, M. (2008). The experience of living with dementia in residential care: an interpretative phenomenological analysis. The Gerontologist, 48(6), 711-720. doi:10.1093/geront/48.6.711

Delle Fave, A., Brdar, I., Freire, T., Vella-Brodrick, D., \& Wissing, M. P. (2011). The eudaimonic and hedonic components of happiness: Qualitative and quantitative findings. Social Indicators Research, 100(2), 185-207. doi:10.1007/s11205-010-96325

Delle Fave, A., Brdar, I., Wissing, M. P., \& Vella-Brodrick, D. A. (2013). Sources and motives for personal meaning in adulthood. The Journal of Positive Psychology, 8(6), 517-529. doi:10.1080/17439760.2013.830761 
Derdaele, E., Toussaint, L., Thauvoye, E., \& Dezutter, J. (2017). Forgiveness and late life functioning: The mediating role of finding ego-integrity. Aging \& Mental Health, 1-8.

Diener, E., Emmons, R. A., Larsen, R. J., \& Griffin, S. (1985). The satisfaction with life scale. Journal of personality assessment, 49(1), 71-75. doi:10.1207/s15327752jpa4901_13

Diener, E., \& Seligman, M. E. (2002). Very happy people. Psychological science, 13(1), 8184. doi:10.1111/1467-9280.00415

Enkvist, Å., Ekström, H., \& Elmståhl, S. (2012). What factors affect life satisfaction (LS) among the oldest-old? Archives of gerontology and geriatrics, 54(1), 140-145. doi:10.1016/j.archger.2011.03.013

Fry, P. S. (2000). Religious involvement, spirituality and personal meaning for life: Existential predictors of psychological wellbeing in community-residing and institutional care elders. Aging \& Mental Health, 4(4), 375-387. doi:10.1080/713649965

Glaw, X., Kable, A., Hazelton, M., \& Inder, K. (2017). Meaning in life and meaning of life in mental health care: an integrative literature review. Issues in mental health nursing, 38(3), 243-252. doi:10.1080/01612840.2016.1253804

Gleeson, H., Hafford-Letchfield, T., Quaife, M., Collins, D. A., \& Flynn, A. (2018). Preventing and responding to depression, self-harm, and suicide in older people living in long term care settings: a systematic review. Aging \& Mental Health, 1-11. doi:10.1080/13607863.2018.1501666

Grouden, M. E., \& Jose, P. E. (2015). Do sources of meaning differentially predict search for meaning, presence of meaning, and wellbeing. International Journal of Wellbeing, 5(1). doi:10.5502/ijw.v5i1.3 
Henderson, L. W., \& Knight, T. (2012). Integrating the hedonic and eudaimonic perspectives to more comprehensively understand wellbeing and pathways to wellbeing. International Journal of Wellbeing, 2(3), 196-221. doi:10.5502/ijw.v2i3.3.

Huta, V. (2016). An overview of hedonic and eudaimonic well-being concepts. In L.

Reinecke \& M. B. Oliver (Eds.), The Routledge handbook of media use and wellbeing: International perspectives on theory and research on positive media effects (pp. 14-33). New York, NY: Routledge.

Huta, V. (2018). Eudaimonia versus hedonia: What is the difference? And is it real? International Journal of Existential Psychology and Psychotherapy, 7(2), 8.

Iwasaki, Y., Messina, E. S., \& Hopper, T. (2017). The role of leisure in meaning-making and engagement with life. The Journal of Positive Psychology, 1-7. doi:10.1080/17439760.2017.1374443

Kashdan, T. B., Biswas-Diener, R., \& King, L. A. (2008). Reconsidering happiness: The costs of distinguishing between hedonics and eudaimonia. The Journal of Positive Psychology, 3(4), 219-233. doi:10.1080/17439760802303044

Keyes, C. L. M., Shmotkin, D., \& Ryff, C. D. (2002). Optimizing well-being: The empirical encounter of two traditions. Journal of Personality and Social Psychology, 82(6), 1007-1022. doi:10.1037/0022-3514.82.6.1007

Kline, R. B. (2005). Principles and practice of structural equation modeling (2nd ed.). New York, NY: The Guilford Press.

Koenig, H. G., King, D., \& Carson, V. B. (2012). Well-being and positive emotion. In H. G. Koenig, D. King, \& V. B. Carson (Eds.), Handbook of religion and health (2nd ed., pp. 123-144). New York: Oxford University Press, Inc.

Kuykendall, L., Tay, L., \& Ng, V. (2015). Leisure engagement and subjective well-being: A meta-analysis: American Psychological Association. 
Lambert, N. M., Stillman, T. F., Baumeister, R. F., Fincham, F. D., Hicks, J. A., \& Graham, S. M. (2010). Family as a salient source of meaning in young adulthood. The Journal of Positive Psychology, 5(5), 367-376. doi:10.1080/17439760.2010.516616

Lambert, N. M., Stillman, T. F., Hicks, J. A., Kamble, S., Baumeister, R. F., \& Fincham, F. D. (2013). To belong is to matter: Sense of belonging enhances meaning in life. Personality and Social Psychology Bulletin, 39(11), 1418-1427. doi:10.1177/0146167213499186

Martela, F., \& Steger, M. F. (2016). The three meanings of meaning in life: Distinguishing coherence, purpose, and significance. The Journal of Positive Psychology, 11(5), 531545. doi:10.1080/17439760.2015.1137623

Penick, J. M., \& Fallshore, M. (2005). Purpose and meaning in highly active seniors. Adultspan Journal, 4(1), 19-35. doi:10.1002/j.2161-0029.2005.tb00115.x

Podsakoff, P. M., MacKenzie, S. B., \& Podsakoff, N. P. (2012). Sources of method bias in social science research and recommendations on how to control it. Annual Review of Psychology, 63, 539-569. doi:10.1146/annurev-psych-120710-100452

Puvill, T., Lindenberg, J., de Craen, A. J., Slaets, J. P., \& Westendorp, R. G. (2016). Impact of physical and mental health on life satisfaction in old age: a population based observational study. BMC geriatrics, 16(1), 194. doi:10.1186/s12877-016-0365-4

Reker, G. T., \& Wong, P. T. P. (1988). Aging as an individual process: Toward a theory of personal meaning. In J. Birren \& V. Bengston (Eds.), Emergent theories of aging. New York: Springer.

Rosseel, Y. (2012). Lavaan: An R package for structural equation modeling and more. Version 0.5-12 (BETA). Journal of statistical software, 48(2), 1-36. doi:10.18637/jss.v048.i02 
Ryff, C. D. (2013). Psychological well-being revisited: Advances in the science and practice of eudaimonia. Psychotherapy and Psychosomatics, 83(1), 10-28. doi:10.1159/000353263

Schnell, T. (2009). The Sources of Meaning and Meaning in Life Questionnaire (SoMe): Relations to demographics and well-being. The Journal of Positive Psychology, 4(6), 483-499. doi:10.1080/17439760903271074

Slettebø, Å., Sæteren, B., Caspari, S., Lohne, V., Rehnsfeldt, A. W., Heggestad, A. K. T., . . . Lindwall, L. (2017). The significance of meaningful and enjoyable activities for nursing home resident's experiences of dignity. Scandinavian Journal of Caring Sciences, 31(4), 718-726. doi:10.1111/scs.12386

Smith, N., Towers, A.-M., Palmer, S., Beecham, J., \& Welch, E. (2017). Being occupied: supporting 'meaningful activity' in care homes for older people in England. Ageing \& Society, 1-23. doi:10.1017/S0144686X17000678

Steger, M. F., Oishi, S., \& Kashdan, T. B. (2009). Meaning in life across the life span: Levels and correlates of meaning in life from emerging adulthood to older adulthood. The Journal of Positive Psychology, 4(1), 43-52. doi:10.1080/17439760802303127

Steger, M. F., \& Samman, E. (2012). Assessing meaning in life on an international scale: Psychometric evidence for the Meaning in Life Questionnaire-Short Form among Chilean households. International Journal of Wellbeing, 2(3), 182-195. doi:10.5502/ijw.v2.i3.2

Tornstam, L. (1989). Gero-transcendence: A reformulation of the disengagement theory. Aging Clinical and Experimental Research, 1(1), 55-63. 
Table 1

Descriptive statistics of the main variables for Study 1 (residents without dementia) and Study 2 (residents with Alzheimer's disease)

\begin{tabular}{|c|c|c|c|c|c|c|c|c|}
\hline \multirow[t]{3}{*}{ Variable } & \multicolumn{2}{|l|}{$n$} & \multicolumn{2}{|l|}{$\begin{array}{l}\text { Mean } \\
(S D)\end{array}$} & \multicolumn{4}{|c|}{ Percentage of sample $(\%)$} \\
\hline & & & & & Very meaningful & $\begin{array}{l}\text { A little } \\
\text { meaningful }\end{array}$ & $\begin{array}{l}\text { Not so } \\
\text { meaningful }\end{array}$ & $\begin{array}{l}\text { Not at all } \\
\text { meaningful }\end{array}$ \\
\hline & $\mathrm{S} 1$ & $\mathrm{~S} 2$ & $\mathrm{~S} 1$ & $\mathrm{~S} 2$ & $\mathrm{~S} 2$ & $\mathrm{~S} 1$ & $\mathrm{~S} 1$ & $\mathrm{~S} 1$ \\
\hline
\end{tabular}

Sources of meaning (EHHI)

\begin{tabular}{|c|c|c|c|c|c|c|c|c|c|c|c|c|}
\hline Family & 324 & 103 & $\begin{array}{l}3.85 \\
(0.54)\end{array}$ & $\begin{array}{l}3.53 \\
(0.85)\end{array}$ & 91 & 71 & 6 & 17 & 1 & 6 & 2 & 6 \\
\hline Health & 328 & 103 & $\begin{array}{l}3.87 \\
(0.42)\end{array}$ & $\begin{array}{l}3.77 \\
(0.45)\end{array}$ & 89 & 78 & 8 & 21 & 2 & 1 & 1 & - \\
\hline Interpersonal relationships & 328 & 103 & $\begin{array}{l}3.54 \\
(0.84)\end{array}$ & $\begin{array}{l}3.24 \\
(0.94)\end{array}$ & 72 & 50 & 16 & 32 & 7 & 9 & 5 & 9 \\
\hline Leisure & 325 & 101 & $\begin{array}{l}3.39 \\
(0.94)\end{array}$ & $\begin{array}{l}3.03 \\
(1.03)\end{array}$ & 64 & 41 & 19 & 33 & 9 & 1 & 8 & 13 \\
\hline Standard of living & 318 & 99 & $\begin{array}{l}3.36 \\
(0.93)\end{array}$ & $\begin{array}{l}3.06 \\
(0.94)\end{array}$ & 61 & 36 & 20 & 44 & 13 & 10 & 6 & 10 \\
\hline Work & 326 & 102 & $\begin{array}{l}3.16 \\
(1.19)\end{array}$ & $\begin{array}{l}3.16 \\
(0.98)\end{array}$ & 61 & 46 & 13 & 34 & 7 & 9 & 19 & 11 \\
\hline Society \& community & 327 & 99 & $\begin{array}{l}3.34 \\
(0.95)\end{array}$ & $\begin{array}{l}3.30 \\
(0.86)\end{array}$ & 60 & 51 & 21 & 35 & 11 & 8 & 8 & 6 \\
\hline Spirituality/religion & 328 & 102 & $\begin{array}{l}3.03 \\
(1.17)\end{array}$ & $\begin{array}{l}3.15 \\
(1.01)\end{array}$ & 51 & 48 & 22 & 29 & 8 & 12 & 19 & 11 \\
\hline Personal growth & 325 & 100 & $\begin{array}{l}2.78 \\
(1.27)\end{array}$ & $\begin{array}{l}2.88 \\
(1.13)\end{array}$ & 44 & 38 & 18 & 32 & 10 & 10 & 28 & 20 \\
\hline e of Meaning (POM) & 309 & 94 & $\begin{array}{l}2.61 \\
(1.06)\end{array}$ & $\begin{array}{l}2.78 \\
(0.96)\end{array}$ & & & & & & & & \\
\hline tion With Life Scale (SWLS) & 316 & 103 & $\begin{array}{l}3.34 \\
(0.71)\end{array}$ & $\begin{array}{l}3.22 \\
(0.68)\end{array}$ & & & & & & & & \\
\hline
\end{tabular}

Note. For Study 1, the difference between 329 and $n$ is missing data, for Study 2, the difference between 104 and $n$ is missing data. $S D=$ Standard deviation, $\mathrm{S} 1=$ Study $1, \mathrm{~S} 2=$ Study 2. 
Table 2

Bivariate Pearson correlations between the main variables for Study 1

\begin{tabular}{|c|c|c|c|c|c|c|c|c|c|c|c|c|}
\hline & 1 & 2 & 3 & 4 & 5 & 6 & 7 & 8 & 9 & 10 & 11 & 12 \\
\hline Age (1) & 1 & & & & & & & & & & & \\
\hline Family (2) & .052 & 1 & & & & & & & & & & \\
\hline Health (3) & .077 & .091 & 1 & & & & & & & & & \\
\hline Interpersonal relationships (4) & -.072 & $.145^{*}$ & .022 & 1 & & & & & & & & \\
\hline Leisure (5) & -.098 & .085 & $.142 *$ & .052 & 1 & & & & & & & \\
\hline Standard of living (6) & -.037 & $.172 * *$ & .022 & -.017 & $.226 * *$ & 1 & & & & & & \\
\hline Work (7) & -.048 & .046 & .076 & $.185^{* *}$ & $.167 * *$ & -.024 & 1 & & & & & \\
\hline Society \& community (8) & .074 & .037 & .083 & $.320 * *$ & $.201 * *$ & .009 & $.168^{* *}$ & 1 & & & & \\
\hline Spirituality/religion (9) & $.179 * *$ & .076 & -.052 & .103 & .012 & .018 & .096 & $.166^{* *}$ & 1 & & & \\
\hline Personal growth (10) & -.073 & .114 & $.173 * *$ & $.238 * *$ & $.335^{* *}$ & $.217 * *$ & $.230 * *$ & $.311 * *$ & $.133^{*}$ & 1 & & \\
\hline Presence of Meaning (11) & -.059 & $.125^{*}$ & .098 & $.175^{* *}$ & $.209 * *$ & .087 & $.143^{*}$ & .116 & $.181 * *$ & $.269 * *$ & 1 & \\
\hline Satisfaction With Life Scale (12) & .117 & $.159 * *$ & .105 & .010 & $.179 * *$ & .019 & .032 & $.139 *$ & $.124 *$ & .041 & $.218 * *$ & 1 \\
\hline
\end{tabular}

Note. $n=275$ (complete cases after listwise deletions).

$* * * p<.001$; ** $p<.01$; * $p<.05$. 
Table 3

Bivariate Pearson correlations between the main variables for Study 2

\begin{tabular}{|c|c|c|c|c|c|c|c|c|c|c|c|c|}
\hline & 1 & 2 & 3 & 4 & 5 & 6 & 7 & 8 & 9 & 10 & 11 & 12 \\
\hline Age (1) & 1 & & & & & & & & & & & \\
\hline Health (2) & -.021 & 1 & & & & & & & & & & \\
\hline Family (3) & .044 & .195 & 1 & & & & & & & & & \\
\hline Society \& community (4) & -.016 & $.270 *$ & $.480 * * *$ & 1 & & & & & & & & \\
\hline Interpersonal relationships (5) & -.025 & .196 & $.318^{* *}$ & $.256^{*}$ & 1 & & & & & & & \\
\hline Spirituality/religion (6) & .053 & .201 & $.513 * * *$ & $.465 * * *$ & .119 & 1 & & & & & & \\
\hline Work (7) & -.114 & .081 & .090 & $.238 *$ & $.227 *$ & .162 & 1 & & & & & \\
\hline Leisure (8) & -.022 & .130 & .188 & $.402 * * *$ & $.279 * *$ & $.258 *$ & $.323 * *$ & 1 & & & & \\
\hline Personal growth (9) & -.075 & .117 & .187 & $.229 *$ & $.253 *$ & $.306 * *$ & .050 & $.475^{* * *}$ & 1 & & & \\
\hline Standard of living (10) & .020 & $.263 *$ & $.216^{*}$ & $.288 * *$ & $.318 * *$ & $.270^{*}$ & $.312 * *$ & $.520 * * *$ & $.496^{* * *}$ & 1 & & \\
\hline Presence of Meaning (11) & -.080 & .187 & $.334 * *$ & $.360 * *$ & $.270^{*}$ & $.321 * *$ & $.221 *$ & $.425^{* * *}$ & $.340 * *$ & $.352 * *$ & 1 & \\
\hline Satisfaction With Life Scale (12) & -.151 & .044 & $.397 * * *$ & $.221 *$ & .129 & $.285^{* *}$ & .180 & $.248^{*}$ & .016 & .084 & $.483^{* * *}$ & 1 \\
\hline
\end{tabular}

Note. $n=275$ (complete cases after listwise deletions).

$* * * \mathrm{p}<.001 ; * * \mathrm{p}<.01 ; * \mathrm{p}<.05$ 


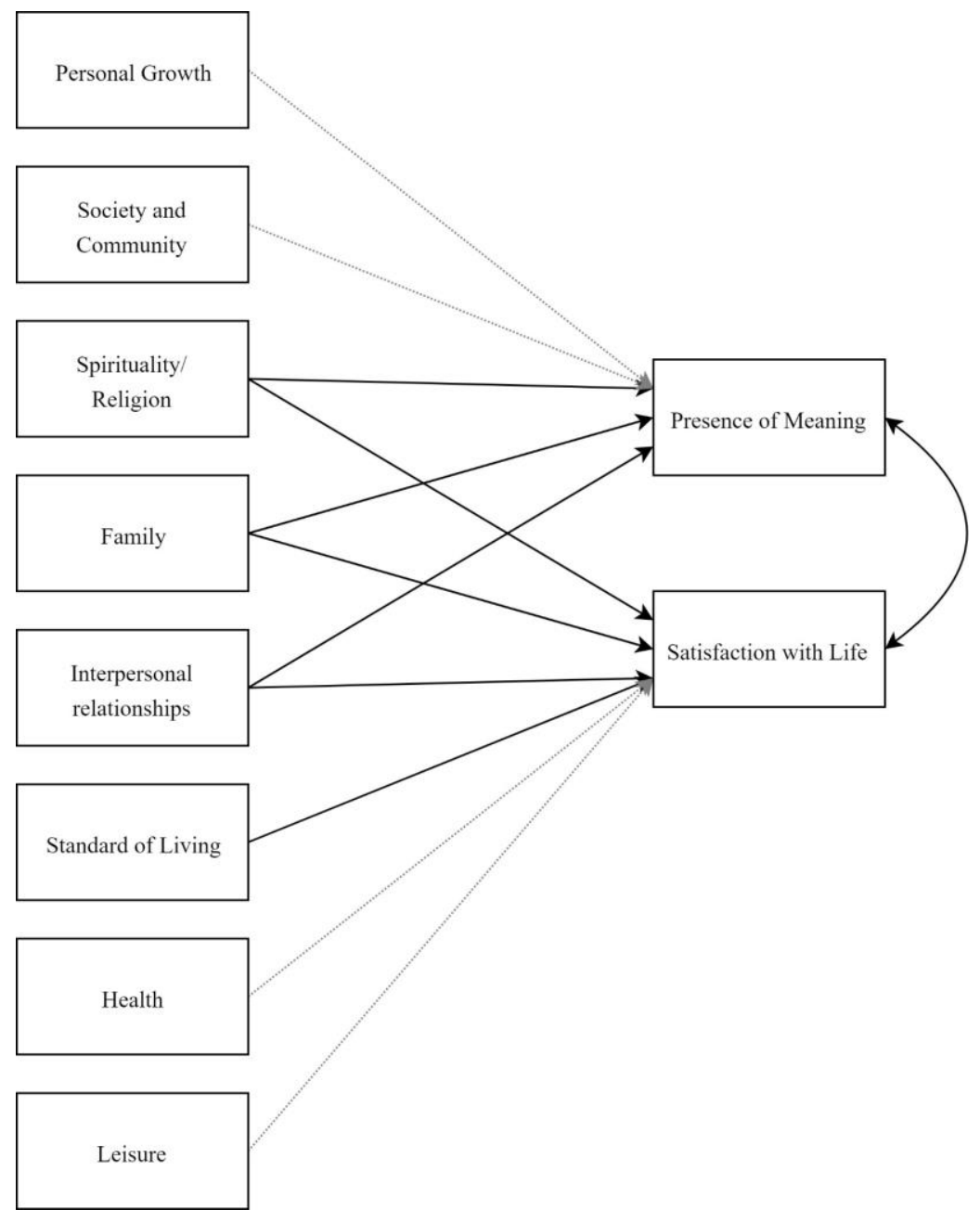

Figure 1. Hypothesized path model. Full black arrows represent predicted pathways, dotted grey arrows represent tentative pathways. Double curved arrow represents residual covariance. 


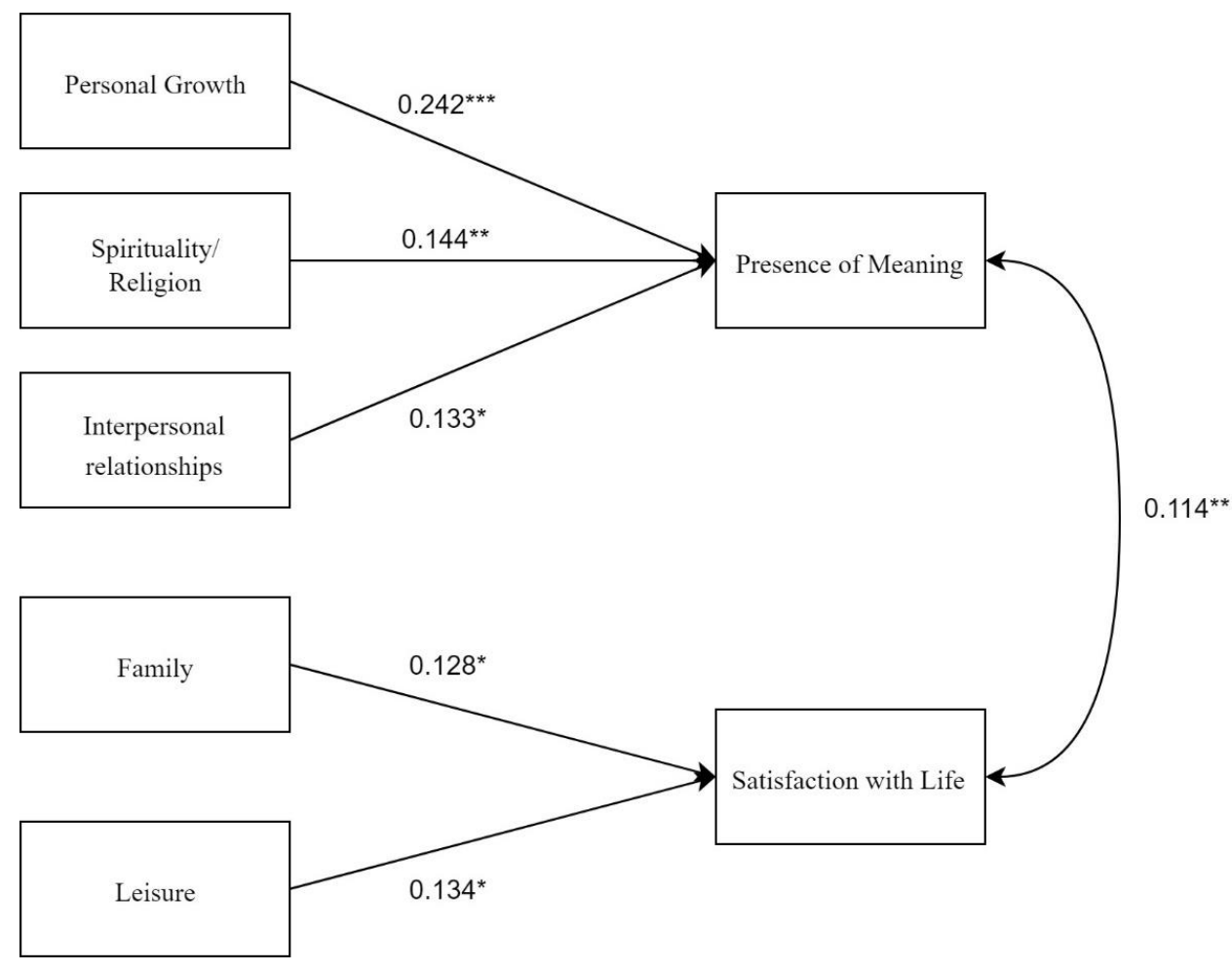

Figure 2. Trimmed parsimonious model showing significantly predictive sources (standardized beta coefficients) for Study 1 ( $n=329)$. Paths from the control variable age are not shown (only significantly related to Satisfaction with Life, $\beta=0.146, p=0.015$ ). Double arrow represents residual covariance.

$* * * p<.001 ; * * p<.01 ; * p<.05$. 


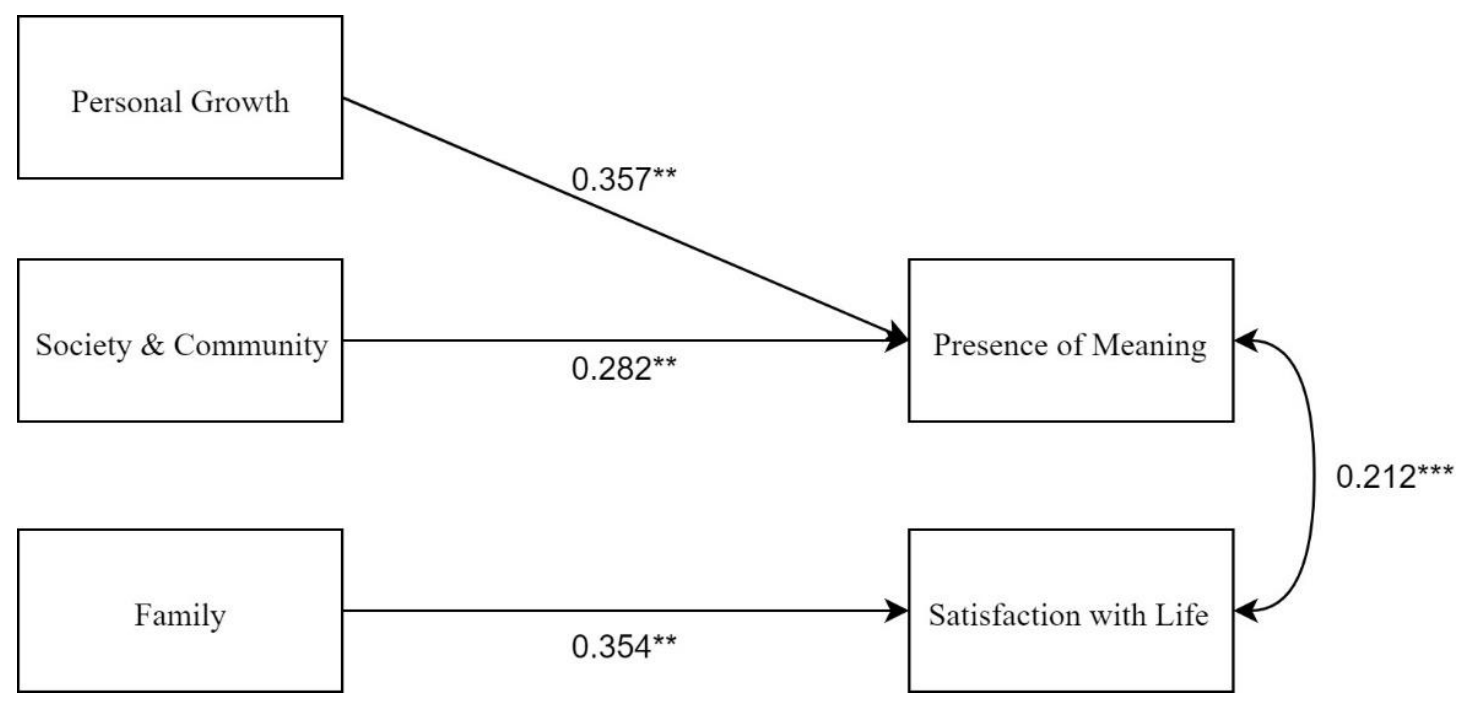

Figure 3. Trimmed parsimonious model showing significantly predictive sources (standardized beta coefficients) for Study $2(n=104)$. Paths from the control variable age are not shown and were not significant. Double arrow represents residual covariance.

$* * * p<.001 ; * * p<.01 ; * p<.05$. 